\title{
Antipsychotics and dementia
}

\author{
P Gareri ${ }^{1,2 *}$, N M Marigliano1', S De Fazio ${ }^{1}$, R Lacava², A Castagna², D S Costantino², G De Sarro ${ }^{1}$ \\ From de Senectute: Age and Health Forum \\ Catanzaro, Italy. 5-7 December 2009
}

\section{Background}

In recent years use of antipsychotics was widely debated for concerns about their safety in elderly patients affected with dementia $[1,2]$.

\section{Materials and methods}

In order to update the use of antipsychotics in elderly demented people, Medline research was done using the words elderly, conventional and atypical antipsychotics, adverse events, dementia, behavioural and psychotic symptoms in dementia (BPSD).

\section{Results}

Conventional antipsychotics have been widely used for BPSD; an efficacy superior to placebo was shown only at high doses, but they were associated to several and severe side effects [1]. Atypical antipsychotics showed an efficacy superior to placebo in randomized studies in BPSD treatment, with better tolerability profile vs. conventional drugs [3]. However, in 2002 trials with risperidone and olanzapine in elderly patients affected with dementia-related psychoses suggested a possible increase in cerebrovascular adverse events [1]. Drug regulatory agencies issued specific recommendations for undelining that the treatment of BPSD with atypical antipsychotics is "off-label" [1]. Conventional antipsychotics were shown to be able as likely as atypical agents to increase the risk of death among elderly persons and should not be used to replace atypical agents discontinued after the FDA warnings [1]. Before prescribing an antipsychotic drug, the presence of cardiovascular diseases, QTc interval on electrocardiogram, electrolytic imbalances, familiar history for torsades des pointes, concomitant treatments and use of drugs able to lengthen QTc have to be closely taken into account. Atypical antipsychotics are probably still the best option for short-term (6-12 weeks) treatment of aggression that is severe, persistent, and treatment resistant, but serious adverse events are a major contraindication to long-term therapy [4].

\section{Conclusions}

Use of atypical antipsychotics in dementia needs a careful case-by-case assessment, together with the possible drug-drug, drug-disease and drug-food interactions.

\section{Author details}

${ }^{1}$ Chair of Pharmacology, Department of Experimental and Clinical Medicine, Faculty of Medicine and Surgery, University Magna Græcia of Catanzaro,

Clinical Pharmacology and Pharmacovigilance Unit, Mater Domini University Hospital, Catanzaro, Italy. ${ }^{2}$ Geriatrist, Operative Unit Elderly Health Care,

Catanzaro, Italy.

Published: 19 May 2010

\section{References}

1. Jeste DV, Blazer D, Casey D, Meeks T, Salzman C, Schneider L, Tariot P, Yaffe K: ACNP White Paper: update on use of antipsychotic drugs in elderly persons with dementia. Neuropsychopharmacology 2008, 33:957-970.

2. Ray WA, Chung CP, Murray KT, Hall K, Stein CM: Atypical antipsychotic drugs and the risk of sudden cardiac death. NEJM 2009, 360:225-235.

3. Gareri P, De Fazio P, Stilo M, Ferreri G, De Sarro G: Conventional and atypical antipsychotics in the elderly. Clin Drug Invest 2003, 23:287-322.

4. Ballard CG, Gauthier S, Cummings $J$, Brodaty H, Grossberg GT, Robert P, Lyketsos CG: Management of agitation and aggression associated with Alzheimer disease. Nat Rev Neurol 2009, 5:245-255.

doi:10.1186/1471-2318-10-S1-A93

Cite this article as: Gareri et al:: Antipsychotics and dementia. BMC Geriatrics 2010 10(Suppl 1):A93. 